\title{
Optimization and characterization of biosurfactant production by Bacillus subtilis isolates towards microbial enhanced oil recovery applications
}

\author{
Jorge F.B. Pereira ${ }^{a}$, Eduardo J. Gudiña ${ }^{b}$, Rita Costa ${ }^{a}$, Rui Vitorino ${ }^{c}$, José A. Teixeira ${ }^{b}$, \\ João A.P. Coutinho ${ }^{a}$, Lígia R. Rodrigues ${ }^{\mathrm{b}, *}$ \\ ${ }^{a}$ CICECO - Chemistry Department, University of Aveiro, Portugal \\ ${ }^{\mathrm{b}}$ IBB - Institute for Biotechnology and Bioengineering, Centre of Biological Engineering, University of Minho, Braga, Portugal \\ ${ }^{\mathrm{c}} \mathrm{QOPNA}$ - Mass spectrometry Center, University of Aveiro, Portugal
}

\section{H I G H L I G H T S}

- Bacillus subtilis isolates from Brazilian crude oils produce biosurfactants under reservoir conditions.

- Sucrose was found to be the best carbon source for biosurfactant production.

- Similar mixtures containing $\mathrm{C}_{13^{-}}, \mathrm{C}_{14^{-}}$and $\mathrm{C}_{15^{-}}$-surfactin were found for the biosurfactants produced.

- Biosurfactants have better interfacial activity and lower critical micellar concentrations than chemical surfactants.

- The produced biosurfactants are promising for Microbial Enhanced Oil Recovery applications.

\section{A R T I C L E I N F O}

\section{Article history:}

Received 28 February 2013

Received in revised form 14 April 2013

Accepted 18 April 2013

Available online 9 May 2013

\section{Keywords:}

Surfactins

Bacillus subtilis

Biosurfactants

MEOR

MALDI-TOF

\begin{abstract}
A B S T R A C T
Biosurfactant production by three Bacillus subtilis strains (\#309, \#311 and \#573) isolated from Brazilian crude oils was optimized based on different carbon and nitrogen sources. The lowest surface tension values were obtained using sucrose containing media for the three isolates. Biosurfactants produced by each strain were characterized by Fourier transform infrared spectroscopy (FTIR), proton nuclear magnetic resonance ( ${ }^{1} \mathrm{H} \mathrm{NMR}$ ), and matrix-assisted laser desorption ionization-time of flight mass spectrometry (MALDI-TOF). The chemical characterization showed that the three isolates produced very similar

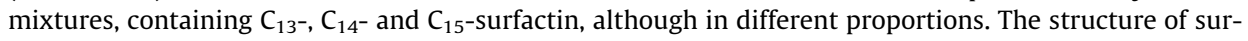
factins produced by the three strains was shown to be in good agreement with their surface-activities. The interfacial-activities of the biosurfactants were characterized and compared with chemical surfactants. Furthermore, the application of biosurfactants and chemical surfactants in oil recovery was evaluated. The results obtained showed that biosurfactants have better interfacial-activity and oil recovery efficiency than common chemical surfactants, thus being more attractive to be applied in Microbial Enhanced Oil Recovery.
\end{abstract}

(ㄷ) 2013 Elsevier Ltd. All rights reserved.

\section{Introduction}

Surface-active agents or surfactants are an important class of chemical compounds used in different sectors of modern industry, such as food, pharmaceutical, cosmetics and petroleum industries $[1,2]$. These compounds are able to reduce surface and interfacial tensions, as well as to form and stabilize oil in water or water in oil emulsions [3]. Structurally they are amphiphilic molecules that comprise both hydrophobic and hydrophilic moieties, being the

\footnotetext{
* Corresponding author. Tel.: +351253 604401; fax: +351 253604429 .

E-mail address: lrmr@deb.uminho.pt (L.R. Rodrigues).
}

apolar component usually a carbon chain, whereas the polar part, more variable, can be ionic (anionic or cationic) or non-ionic [4]. Due to environmental issues and restrictive laws, the demand for biodegradable surfactants and naturally produced by microorganisms is increasing [5]. The use of these bio-compounds as an alternative to the traditional chemical surfactants has been impelled by the fast progress of biotechnology and also by their interesting features, including their lower toxicity, higher biodegradability and effectiveness at extreme temperature, salinity and $\mathrm{pH}$ conditions $[2,6]$. Furthermore, biosurfactants exhibit high surface-activities together with low critical micelle concentrations (CMCs), being in some cases even lower than most of the traditional chemicals surfactants [6]. 
Despite all these advantages, only a few biosurfactants are produced at large scale for commercial applications, mainly due to their considerable production and recovery costs [7]. In the last years, aiming a large industrial application of biosurfactants, the use of novel resources, raw materials and new microorganisms has been explored to reduce the production costs and to increase their effectiveness [8-14]. Many biosurfactants have been described, being glycolipids $[15,16]$ and lipopeptides $[4,17]$ the most common. Lipopeptides are produced, among others, by several Bacillus species. They are constituted by a peptide (hydrophilic moiety) linked to a fatty acid (hydrophobic component) [4]. Surfactin, produced by Bacillus subtilis strains, is the best studied lipopeptide biosurfactant. It consists of a long-chain $\beta$-hydroxy fatty acid whose two functional groups close a short peptidic moiety composed by seven amino acid residues $[18,19]$. The surfactins are classified in three different types (A, B and C) according to their amino acid sequences [20]. B. subtilis strains do not produce a unique type of surfactin, and a natural diversity of homologues occur, which differ in the length and ramification of the fatty acid chains, and isoforms, characterized by some differences in the peptidic sequence [18]. Different isoforms and homologues exhibit different properties and activities. As the surfactin name indicates, this biosurfactant exhibits an exceptional surface activity, and is among the most effective biosurfactants known so far, being able to decrease the surface tension of water from 72 to $27 \mathrm{mN} \mathrm{m}^{-1}$ at concentrations as low as $0.005 \%$ [21].

These compounds are considered powerful biosurfactants [22], and can be used by the petroleum industry in MEOR processes and bioremediation [2], as well as by many other industries such as the biomedical industry as therapeutic agents $[19,20]$. Among several potential applications of surfactin, its use in MEOR represents one of the most promising methods to recover substantial amounts of the residual oil entrapped in mature oil fields [23,24]. The replacement of conventional synthetic surfactants by these biocompounds appears to be a good and efficient approach; however it still depends on the strategy adopted. The use of biosurfactants in MEOR can be performed in two different ways. In the first one, biosurfactants are produced ex situ, and subsequently injected into the reservoir. The other option is to produce the biosurfactant in situ by stimulation and/or injection of indigenous microorganisms. The first approach is limited by the costs involved in the biosurfactant production and purification processes. On the other hand, the costs involved in the second approach are apparently lower; however it requires that the microorganisms used are properly stimulated and able to produce sufficient amounts of the biosurfactant [23].

Moreover, taking into account the use of surfactins in in situ MEOR processes, the greatest challenge is to isolate microorganisms able to grow under anaerobic conditions, high salinities, temperatures and pressures. Several reports have described the isolation of $B$. subtilis strains from oil reservoirs [24-27], which suggest that these organisms can be successfully used under reservoir conditions. Recently, Gudiña et al. [28] isolated several B. subtilis strains from a Brazilian oil reservoir that were able to produce different biosurfactants under aerobic and anaerobic conditions. Among them, three different strains produced biosurfactants with interesting surface-activities and emulsifying properties.

Therefore, aiming at the further use of these B. subtilis strains in MEOR processes, the biosurfactant production yields must be improved which can be achieved through the optimization of culture media, specifically of the carbon and nitrogen sources. In this work, biosurfactant production by the three $B$. subtilis strains previously isolated [28] was optimized through a proper manipulation of carbon and nitrogen sources. The biosurfactants produced by each strain were characterized by ${ }^{1} \mathrm{H}$ NMR, FTIR and MALDI-TOF, and their abilities to influence the interfacial tension of water/oil systems and enhance oil recovery were evaluated and compared with chemical surfactants.

\section{Experimental}

\subsection{Microorganisms}

Three biosurfactant-producing B. subtilis strains (\#309, \#311 and \#573) previously isolated from crude oil samples obtained from a Brazilian oil field [28] were used. Isolates were stored at $-80^{\circ} \mathrm{C}$ in LB medium supplemented with $20 \%(\mathrm{v} / \mathrm{v})$ glycerol solution. The composition of LB medium was $\left(\mathrm{g} \mathrm{l}^{-1}\right)$ : NaCl 10.0; tryptone 10.0; yeast extract 5.0. The $\mathrm{pH}$ was adjusted to 7.0.

\subsection{Chemical surfactants}

Two chemical surfactants (Enordet and Petrostep) commonly used in chemical enhanced oil recovery (CEOR) were studied and their interfacial activities compared with biosurfactants produced by $B$. subtilis strains.

\subsection{Effect of carbon and nitrogen sources on growth and biosurfactant production}

Growth and biosurfactant production by the three isolates was evaluated using Mineral Salt Solution (MSS) with different carbon

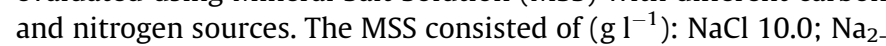
$\mathrm{HPO}_{4}$ 5.0; $\mathrm{KH}_{2} \mathrm{PO}_{4} 2.0 ; \mathrm{MgSO}_{4} 7 \mathrm{H}_{2} \mathrm{O}$ 0.2. The carbon sources evaluated were: sodium acetate $(A C)$, sodium citrate $(\mathrm{CI})$, fructose (FRU), glucose (GLU), glycerol (GLY), $n$-hexadecane (HEX), lactose (LAC), meat extract (ME), paraffin (PAR), sucrose (SUC), tryptone (TRY) and yeast extract (YE), using ammonium nitrate as the nitrogen source $\left(2 \mathrm{~g} \mathrm{l}^{-1}\right)$. The different carbon sources were added to the MSS at a concentration of $10 \mathrm{~g} \mathrm{l}^{-1}$. The nitrogen sources tested were: ammonium citrate (AC), ammonium nitrate (AN), ammonium sulfate (AS), meat extract (ME), sodium nitrate (SN), tryptone (TRY), urea (U) and yeast extract (YE), keeping sucrose as the carbon source $\left(10 \mathrm{~g} \mathrm{l}^{-1}\right)$. The different nitrogen sources were added to the MSS at a concentration of $2 \mathrm{~g}^{-1}$. All media were adjusted to $\mathrm{pH}$ 7.0.

Assays were performed in $100 \mathrm{ml}$ flasks containing $50 \mathrm{ml}$ of the different media. Each flask was inoculated with $1 \%$ of a pre-culture grown in the same medium for $24 \mathrm{~h}$. Cultures were incubated at $40{ }^{\circ} \mathrm{C}$ without shaking for $120 \mathrm{~h}$. Samples were taken at different times during the fermentation to determine biomass concentration and biosurfactant production. Bacterial growth was determined by measuring the optical density at $600 \mathrm{~nm}$. Afterwards, the samples were centrifuged $\left(10,000 \mathrm{~g}, 20 \mathrm{~min}, 20^{\circ} \mathrm{C}\right)$ and the cell-free supernatants were used to measure surface tension and emulsifying activity. At the end of the fermentation, cells were harvested by centrifugation and dry cell weight $\left(\mathrm{g} \mathrm{l}^{-1}\right)$ was determined $(48 \mathrm{~h}$ at $\left.105^{\circ} \mathrm{C}\right)$.

To recover the biosurfactants, cell-free supernatants were subjected to an acid precipitation. Briefly, the supernatants were adjusted to $\mathrm{pH} 2.0$ with $\mathrm{HCl} 6 \mathrm{M}$ and left overnight at $4{ }^{\circ} \mathrm{C}$. Afterwards, the precipitate was collected by centrifugation $\left(10,000 \mathrm{~g}, 20 \mathrm{~min}, 4^{\circ} \mathrm{C}\right)$ and washed twice with acidified water ( $\mathrm{pH}$ 2.0). The precipitated biosurfactants were dissolved in a minimal amount of demineralised water and the $\mathrm{pH}$ was adjusted to 7.0 using $\mathrm{NaOH} 1 \mathrm{M}$. Finally, the biosurfactant solutions were freeze dried and the products obtained were weighed.

\subsection{Surface-activity determination}

Surface tension measurements of culture broth supernatants and chemical surfactants solutions were performed according to 
the Ring method described elsewhere [29]. A KRÜSS K6 Tensiometer (KRÜSS GmbH, Hamburg, Germany) equipped with a $1.9 \mathrm{~cm}$ De Noüy platinum ring was used. Whenever required, the culture broth supernatants were diluted 10 times $\left(\mathrm{ST}^{-1}\right)$ or 100 times $\left(\mathrm{ST}^{-2}\right)$ with $\mathrm{PBS}\left(10 \mathrm{mM} \mathrm{KH} \mathrm{KO}_{4} / \mathrm{K}_{2} \mathrm{HPO}_{4}\right.$ plus $150 \mathrm{mM} \mathrm{NaCl}$ with $\mathrm{pH}$ adjusted to 7.0) and the surface tension was measured as described above. The CMCs of chemical surfactants dissolved in demineralised water were calculated as described elsewhere [29]. To increase the accuracy of the surface tension measurements, an average of triplicates was determined. All measurements were performed at room temperature $\left(20^{\circ} \mathrm{C}\right)$.

\subsection{Emulsifying activity determination}

Emulsifying activity was determined by the addition of $2 \mathrm{ml}$ of $n$-hexadecane to the same volume of cell-free culture broth supernatant in glass test tubes. The tubes were mixed with vortex at high speed for 2 min and subsequently incubated at $25{ }^{\circ} \mathrm{C}$ for $24 \mathrm{~h}$. The stability of the emulsion was determined after $24 \mathrm{~h}$, and the emulsification index $\left(\mathrm{E}_{24}\right)$ was calculated as the percentage of the height of the emulsified layer $(\mathrm{mm})$ divided by the total height of the liquid column ( $\mathrm{mm}$ ). All emulsification indexes were performed in triplicate.

\subsection{Interfacial-activity determination}

Concentrations ranging from 0.001 to $0.1 \mathrm{~g} \mathrm{l}^{-1}$ of crude biosurfactants recovered from the different isolates were prepared in brine solution ( $50 \mathrm{~g} \mathrm{l}^{-1} \mathrm{NaCl}$ with $\mathrm{pH}$ adjusted to 6.0). These conditions were previously established as optimal for the activity of biosurfactants under study [28]. The chemical surfactants were dissolved in demineralised water at different concentrations up to $1 \mathrm{~g} \mathrm{l}^{-1}$. Arabian light crude oil used in these experiments was kindly provided by GALP (Portugal). Interfacial tension of the water/oil system at different biosurfactant/chemical surfactant concentrations was measured using a Dataphysics contact angle system OCA-20. The method consisted in the analysis of the shape of a pendant drop by fitting to the Young-Laplace equation. A Hamilton DS 500/GT syringe connected to a stainless steel needle placed inside a glass chamber with the biosurfactant aqueous solution at room temperature was used to set a fixed drop oil volume $(5.00 \pm 0.15 \mu \mathrm{l})$. For each biosurfactant concentration, at least three independent measures were conducted. For each drop, data was recorded immediately after the drop volume was reached $(5 \mu \mathrm{l})$ and continued during $1 \mathrm{~min}$ (an average of 80 images was captured per drop). The drop shape was analyzed with the software modules SCA 20, using the gravitational acceleration $\left(g=9.8018 \mathrm{~m} \mathrm{~s}^{-2}\right)$ and latitude (lat $=40^{\circ}$ ) values in accordance with the assay location. The density values required for the calculation of the interfacial tensions from the drop image data were acquired using a Viscometer Anton Paar (Model SVM 3000).

\subsection{Extraction and purification of biosurfactants}

Biosurfactants for chemical composition analysis were extracted from cell-free supernatants using the Folch extraction method that is commonly used to extract lipids from biomolecules. The Folch extraction procedure was performed as described elsewhere [30]. Briefly, a chloroform/methanol mixture (2:1) was added to the supernatant sample to a final chloroform/methanol/ water ratio of $8: 4: 3$. The mixture was centrifuged $(9000 \mathrm{~g}, 5 \mathrm{~min}$ ), the organic layer was collected and the samples were evaporated to dryness under $\mathrm{N}_{2}$ at $37{ }^{\circ} \mathrm{C}$ for $30 \mathrm{~min}$. Prior to NMR spectroscopy and mass spectrometry analysis, the samples were re-dissolved in chloroform.

\subsection{Fourier transform infrared spectroscopy}

The solid biosurfactant extracts recovered from the supernatants of the three $B$. subtilis isolates were characterized by Fourier transform infrared spectroscopy (FTIR). The FTIR spectra, with a resolution of $4 \mathrm{~cm}^{-1}$, were collected from 400 to 4000 wavenumbers $\left(\mathrm{cm}^{-1}\right)$, and is an average of 128 scans using a Tensor 27 Infrared Spectrometer operating in the attenuated total reflection (ATR) mode (equipped with a single horizontal Golden Gate ATR cell).

\subsection{Nuclear magnetic resonance spectroscopy}

The extracted biosurfactants were re-dissolved in deuterated chloroform $\left(\mathrm{CDCl}_{3}\right)$ and the respective ${ }^{1} \mathrm{H}$ NMR spectra were recorded at $25^{\circ} \mathrm{C}$ using a Bruker Avance 300 spectrometer operating at $300.13 \mathrm{MHz}$. Chemical shifts $(\delta)$ are given on the ppm scale relative to tetramethylsilane (TMS).

\subsection{Mass spectrometry}

The extracted biosurfactants were dissolved at a concentration of $2 \mathrm{~g} \mathrm{l}^{-1}$ in a solution composed of $50 \%$ acetonitrile (ACN), 50\% water, and $0.1 \%$ trifluoroacetic acid (TFA). The samples were mixed (1:1) with a matrix consisting of a saturated solution of $\alpha$-cyano-4hydroxycinnamic acid prepared in 50\% ACN/0.1\% TFA. An aliquot of $1 \mu \mathrm{L}$ of each sample/matrix mixture was spotted onto the MALDI sample and slowly dried to allow matrix crystallization. Then, the extracted biosurfactants were analyzed by mass spectrometry (MS) using a MALDI-TOF/TOF mass spectrometer (4800 Proteomics Analyzer, Applied Biosystems, Europe) in the positive ion reflector mode. Spectra were obtained in the mass range between 800 and 4500 Da with ca. 1500 laser shots, thus providing a mass resolution of about 18,000 (FWMH) and amass accuracy of 20-25 ppm. MS data were processed using Data Explorer 4.4 (Applied Biosystems).

\subsection{Application of chemical surfactants and biosurfactants in removal of crude oil from sand}

The applicability of biosurfactants produced by B. subtilis \#309, \#311 and \#573 and the chemical surfactants Enordet and Petrostep in oil recovery was evaluated using artificially contaminated sand containing 10\% (w/w) of Arabian Light oil. Samples of $40 \mathrm{~g}$ of sand were mixed with $4 \mathrm{~g}$ of crude oil in $100 \mathrm{ml}$ Erlenmeyer flasks by shaking and allowed to age for $24 \mathrm{~h}$. Afterwards, $40 \mathrm{ml}$ of biosurfactants and commercial surfactants solutions at a concentration of $1 \mathrm{~g} \mathrm{l}^{-1}$ were added to each flask. The flasks were incubated at $100 \mathrm{rpm}$ and $40^{\circ} \mathrm{C}$ for $24 \mathrm{~h}$. Afterwards, the oil removed was recovered from the surface and its volume was measured. Control assays were performed using demineralized water at the same conditions. All the experiments were carried out in triplicate.

\section{Results and discussion}

\subsection{Effect of carbon and nitrogen sources on growth and biosurfactant production}

To determine the optimal conditions that yield the highest biosurfactant production by $B$. subtilis \#309, \#311 and \#573, the effect of various carbon and nitrogen sources was evaluated. The three isolates were able to grow in all carbon sources tested, except for $n$-hexadecane. When paraffin was used as the sole carbon source, a slight growth was observed for all isolates, however lower than the obtained with the water soluble carbon sources tested (Table 1). Several authors reported, with different Bacillus strains, that the use of hydrocarbons (including $n$-hexadecane and paraffin) as 


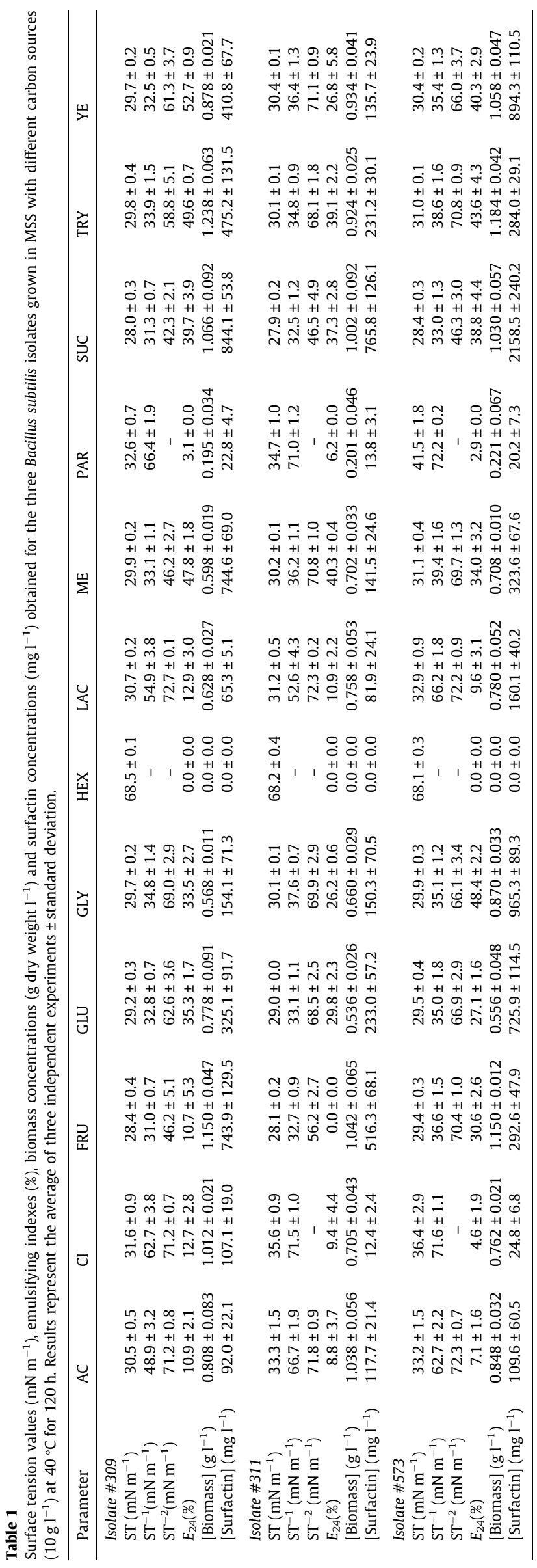

the only carbon source inhibited bacterial growth and biosurfactant production [31-33], or resulted in poor growth and biosurfactant production [34].

The highest biomass production, expressed as dry cell weight, was obtained with tryptone and fructose for isolates \#309 and \#573, and with fructose and sodium acetate for isolate \#311 (Table 1). Glucose and sucrose were reported as the best carbon sources for growth using different Bacillus isolates [31,32], although Joshi et al. [34] obtained better results with fructose.

The lowest surface tension values $\left(\mathrm{ST}^{-2}\right)$ were obtained when sucrose was used as the sole carbon source for all the isolates. The surface tension values were between 27.9 and $28.4 \mathrm{mN} \mathrm{m}^{-1}$, and the $\mathrm{ST}^{-2}$ values between 46.5 and $42.3 \mathrm{mN} \mathrm{m}^{-1}$ (Table 1). Fructose also offered good results regarding surface tension reduction $\left(\mathrm{ST}^{-2}\right)$ for isolate \#309. The use of lactose as carbon source resulted in high surface tension values when compared with the other the carbohydrates tested.

This is in agreement with the results reported by other authors for different $B$. subtilis isolates. Several authors obtained the lowest surface tension values using glucose or sucrose [31-35] as the sole carbon sources. Abdel-Mawgoud et al. [31] also found a poor biosurfactant production using lactose as the sole carbon source. On the other hand, the use of hydrocarbons as the sole carbon source usually resulted in no biosurfactant production $[31,32,34]$. In the case of $B$. subtilis \#309, \#311 and \#573, the combination of a water soluble carbon source (sucrose) and a hydrocarbon ( $n$-hexadecane) did not have a negative effect on the biosurfactant production [28].

Regarding the emulsifying activity, the complex carbon sources tested (meat extract, tryptone and yeast extract) were amongst the most favorable. For isolate \#309, the highest emulsifying activity was obtained with yeast extract (52.7\%), and similar results were obtained with tryptone and meat extract (49.6\% and $47.8 \%$, respectively). For isolate \#311, the best result was obtained with meat extract (40.3\%), followed by tryptone (39.1\%) and sucrose (37.3\%). For isolate \#573, the highest emulsifying activity was obtained with glycerol (48.4\%), followed by tryptone (43.6\%) and yeast extract (40.3\%). Raw glycerol, a by-product from biodiesel production plants, can be used as a low-cost carbon source for biosurfactant production [36,37]. Furthermore, Dastgheib et al. [33] found the highest emulsifying activity using yeast extract as the carbon source, followed by sucrose, fructose and glucose, whereas the use of lactose resulted in poor emulsifying activity. For the three isolates, the highest amount of biosurfactant produced (expressed as mg of biosurfactant per liter) was obtained when using sucrose as the carbon source. The amounts of crude biosurfactant produced were 844,755 and $2158 \mathrm{mg} \mathrm{l}^{-1}$ for isolates \#309, \#311 and \#573, respectively. The highest amount of biosurfactant produced is in agreement with the lowest surface tension values $\left(\mathrm{ST}^{-2}\right)$ obtained for all the isolates, but curiously not with the highest emulsifying activities, thus suggesting that different types of biosurfactants with different properties are being synthesized depending on the carbon sources used.

Regarding the nitrogen sources, the highest biomass production was obtained using meat extract as the sole nitrogen source for isolates \#309 and \#311. For isolate \#573, yeast extract and meat extract gave a similar result (Table 2 ).

The lowest surface tension values $\left(\mathrm{ST}^{-2}\right)$, which corresponded to the highest biosurfactant productions, were obtained with yeast extract for isolate \#309 (38.3 $\left.\mathrm{mN} \mathrm{m}^{-1}\right)$; ammonium sulfate and ammonium nitrate for isolate \#573 (44.6 and $46.3 \mathrm{mN} \mathrm{m}^{-1}$, respectively); and for the isolate \#311, yeast extract and ammonium sulfate gave similar results $\left(39.2\right.$ and $37.0 \mathrm{mN} \mathrm{m}^{-1}$, respectively). The highest biosurfactant productions were 931, 980 and $2288 \mathrm{mg} \mathrm{l}^{-1}$ for isolates \#309, \#311 and \#573, respectively. Other authors reported crude biosurfactant productions between 720 and $1120 \mathrm{mg} \mathrm{l}^{-1}$ [31,32]. Isolate \#573 produced higher amounts 
Table 2

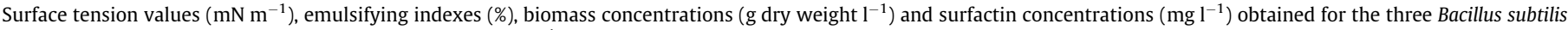
isolates grown in MSS with different nitrogen sources $\left(2 \mathrm{~g} \mathrm{l}^{-1}\right)$ at $40^{\circ} \mathrm{C}$ for $120 \mathrm{~h}$. Results represent the average of three independent experiments \pm standard deviation.

\begin{tabular}{|c|c|c|c|c|c|c|c|c|}
\hline Parameter & AC & AN & AS & ME & SN & TRY & $\mathrm{U}$ & YE \\
\hline \multicolumn{9}{|l|}{ Isolate \#309 } \\
\hline $\mathrm{ST}\left(\mathrm{mN} \mathrm{m}^{-1}\right)$ & $28.5 \pm 0.5$ & $28.0 \pm 0.3$ & $28.4 \pm 0.2$ & $29.0 \pm 0.2$ & $29.3 \pm 0.2$ & $30.2 \pm 0.2$ & $29.6 \pm 0.2$ & $28.7 \pm 0.3$ \\
\hline $\mathrm{ST}^{-1}\left(\mathrm{mN} \mathrm{m}^{-1}\right)$ & $31.1 \pm 0.7$ & $31.3 \pm 0.7$ & $31.3 \pm 0.2$ & $32.0 \pm 0.6$ & $31.9 \pm 0.8$ & $39.9 \pm 1.9$ & $31.9 \pm 0.9$ & $30.8 \pm 0.4$ \\
\hline $\mathrm{ST}^{-2}\left(\mathrm{mN} \mathrm{m}^{-1}\right)$ & $42.3 \pm 5.3$ & $42.3 \pm 2.1$ & $44.0 \pm 2.7$ & $47.8 \pm 3.4$ & $45.6 \pm 5.4$ & $70.4 \pm 0.8$ & $44.4 \pm 2.4$ & $38.3 \pm 1.8$ \\
\hline$E_{24}(\%)$ & $32.3 \pm 1.5$ & $39.7 \pm 3.9$ & $11.2 \pm 1.8$ & $0.0 \pm 0.0$ & $41.0 \pm 2.8$ & $0.0 \pm 0.0$ & $31.2 \pm 8.8$ & $43.3 \pm 6.7$ \\
\hline [Biomass] $\left(\mathrm{g} \mathrm{l}^{-1}\right)$ & $1.270 \pm 0.044$ & $1.066 \pm 0.092$ & $1.184 \pm 0.065$ & $1.662 \pm 0.044$ & $1.243 \pm 0.032$ & $1.396 \pm 0.074$ & $0.997 \pm 0.032$ & $1.534 \pm 0.094$ \\
\hline [Surfactin] $\left(\mathrm{mg} \mathrm{l}^{-1}\right)$ & $789.3 \pm 107.6$ & $844.1 \pm 53.8$ & $799.6 \pm 67.9$ & $703.2 \pm 85.6$ & $758.2 \pm 138.5$ & $110.5 \pm 25.0$ & $790.7 \pm 62.2$ & $931.8 \pm 42.7$ \\
\hline \multicolumn{9}{|l|}{ Isolate \#311 } \\
\hline $\mathrm{ST}\left(\mathrm{mN} \mathrm{m}^{-1}\right)$ & $28.5 \pm 0.4$ & $27.9 \pm 0.2$ & $28.5 \pm 0.2$ & $28.5 \pm 0.2$ & $29.5 \pm 0.3$ & $29.1 \pm 0.1$ & $29.4 \pm 0.1$ & $28.7 \pm 0.4$ \\
\hline $\mathrm{ST}^{-1}\left(\mathrm{mN} \mathrm{m}^{-1}\right)$ & $31.3 \pm 0.2$ & $32.5 \pm 1.2$ & $31.3 \pm 1.8$ & $30.6 \pm 1.2$ & $33.0 \pm 0.6$ & $31.5 \pm 0.7$ & $35.0 \pm 0.7$ & $31.2 \pm 0.8$ \\
\hline $\mathrm{ST}^{-2}\left(\mathrm{mN} \mathrm{m}^{-1}\right)$ & $44.1 \pm 4.0$ & $46.5 \pm 4.9$ & $37.0 \pm 1.7$ & $43.2 \pm 2.8$ & $55.4 \pm 4.2$ & $54.0 \pm 2.6$ & $68.7 \pm 3.3$ & $39.2 \pm 6.1$ \\
\hline$E_{24}(\%)$ & $4.7 \pm 2.2$ & $37.3 \pm 2.8$ & $0.0 \pm 0.0$ & $0.0 \pm 0.0$ & $37.2 \pm 3.2$ & $0.0 \pm 0.0$ & $25.0 \pm 7.1$ & $32.8 \pm 2.2$ \\
\hline [Biomass] $\left(\mathrm{g} \mathrm{l}^{-1}\right)$ & $1.404 \pm 0.038$ & $1.002 \pm 0.092$ & $0.934 \pm 0.041$ & $1.632 \pm 0.023$ & $1.080 \pm 0.062$ & $0.954 \pm 0.032$ & $0.874 \pm 0.088$ & $1.242 \pm 0.024$ \\
\hline [Surfactin] $\left(\mathrm{mg} \mathrm{l}^{-1}\right)$ & $828.9 \pm 103.1$ & $765.8 \pm 126.1$ & $980.7 \pm 45.4$ & $851.0 \pm 73.0$ & $537.1 \pm 107.5$ & $574.6 \pm 66.2$ & $196.6 \pm 85.8$ & $980.1 \pm 46.7$ \\
\hline \multicolumn{9}{|l|}{ Isolate \#573 } \\
\hline $\mathrm{ST}\left(\mathrm{mN} \mathrm{m}^{-1}\right)$ & $30.3 \pm 0.9$ & $28.4 \pm 0.3$ & $29.6 \pm 0.7$ & $30.0 \pm 0.1$ & $29.9 \pm 0.6$ & $32.7 \pm 0.6$ & $30.1 \pm 0.5$ & $29.5 \pm 0.5$ \\
\hline $\mathrm{ST}^{-1}\left(\mathrm{mN} \mathrm{m}^{-1}\right)$ & $34.3 \pm 2.5$ & $33.0 \pm 1.3$ & $32.6 \pm 0.3$ & $36.3 \pm 1.1$ & $35.2 \pm 2.0$ & $53.2 \pm 2.4$ & $32.6 \pm 0.5$ & $33.6 \pm 1.5$ \\
\hline $\mathrm{ST}^{-2}\left(\mathrm{mN} \mathrm{m}^{-1}\right)$ & $54.4 \pm 5.4$ & $46.3 \pm 3.0$ & $44.6 \pm 2.7$ & $57.9 \pm 4.1$ & $57.5 \pm 5.5$ & $71.7 \pm 0.2$ & $51.6 \pm 5.1$ & $56.7 \pm 5.1$ \\
\hline$E_{24}(\%)$ & $33.3 \pm 1.5$ & $38.8 \pm 4.4$ & $35.0 \pm 2.3$ & $0.0 \pm 0.0$ & $41.7 \pm 1.8$ & $0.0 \pm 0.0$ & $27.3 \pm 5.6$ & $25.0 \pm 7.1$ \\
\hline [Biomass] $\left(\mathrm{g} \mathrm{l}^{-1}\right)$ & $1.154 \pm 0.050$ & $1.030 \pm 0.057$ & $1.466 \pm 0.065$ & $1.708 \pm 0.030$ & $1.020 \pm 0.044$ & $1.562 \pm 0.015$ & $1.500 \pm 0.029$ & $1.762 \pm 0.080$ \\
\hline [Surfactin] $\left(\mathrm{mg} \mathrm{l}^{-1}\right)$ & $1500.2 \pm 251.5$ & $2158.5 \pm 240.2$ & $2288.9 \pm 210.5$ & $1369.9 \pm 169.9$ & $1129.5 \pm 266.7$ & $157.8 \pm 16.8$ & $1853.5 \pm 305.7$ & $1496.9 \pm 300.6$ \\
\hline
\end{tabular}

of biosurfactant when compared with isolates \#309 and \#311. The critical micelle concentrations for these crude biosurfactants were determined in a previous work: $20 \mathrm{mg} \mathrm{l}^{-1}$ for isolates \#309 and \#311, and $30 \mathrm{mg} \mathrm{l}^{-1}$ for isolate \#573 [28]. Therefore, biosurfactants produced by isolates \#309 and \#311 are more efficient than the ones produced by isolate \#573, which explains why isolate \#573 although producing higher amounts of biosurfactant provides similar (or higher, i.e. less active surfactant) surface tension values than the obtained with the other two isolates.

Abdel-Mawgoud et al. [31] reported the highest biosurfactant production using sodium nitrate and ammonium nitrate as nitrogen sources. Other authors reported the highest biosurfactant production using urea [32,35]. Some Bacillus isolates do not use ammonium sulfate for growth or biosurfactant production, but they can use ammonium nitrate, potassium nitrate or sodium nitrate [32].

The highest emulsifying indexes were obtained with sodium nitrate for isolate \#573 (41.7\%); while for isolate \#309, similar results were obtained using yeast extract and sodium nitrate (43.3\% and $41.0 \%$, respectively); and for isolate \#311, the highest emulsifying indexes were obtained with ammonium nitrate and sodium nitrate (37.3\% and $37.2 \%$, respectively). Dastgheib et al. [33] reported that sodium nitrate was the best substrate for emulsifier production, followed by urea, yeast extract and peptone.

Taking into account the amounts of biosurfactant produced with the different carbon and nitrogen sources, and in order to standardize the medium for all isolates, sucrose and ammonium nitrate were selected for the production of biosurfactants to be further used in the chemical characterization experiments. Moreover, the use of sucrose and ammonium nitrate represents a good compromise between biosurfactant yields and the costs associated with their production. More complex nitrogen sources provide higher emulsification indexes; however their cost is also higher which makes a potential application in MEOR economically unfeasible. Also, this medium was found to be adequate for the three isolates (i.e. could be considered as standard medium) and nitrate is crucial for microbial growth under the low oxygen concentrations present in reservoirs.

\subsection{Chemical characterization}

\subsubsection{FTIR-ATR}

Firstly, fast and direct characterizations of the biosurfactants produced by each isolate were performed using a FTIR-ATR analysis
(Fig. 1). The spectra obtained for the three isolates showed a great similarity between them. It can be clearly observed characteristic absorbance bands of peptides at $3305 \mathrm{~cm}^{-1}$ (NH-stretching mode); at $1643 \mathrm{~cm}^{-1}\left(1645 \mathrm{~cm}^{-1}\right.$ for isolate $\left.\# 311\right)$ resulting from the stretching mode of the $\mathrm{CO}-\mathrm{N}$ bond; and at $1543 \mathrm{~cm}^{-1}$ from the deformation mode of the $\mathrm{N}-\mathrm{H}$ bond combined with $\mathrm{C}-\mathrm{N}$ stretching mode. In addition, it is also clear the presence of aliphatic chains (-CH3; -CH2-), represented by the bands between 2957$2855 \mathrm{~cm}^{-1}$, and $1465-1368 \mathrm{~cm}^{-1}$. The band observed at $1734 \mathrm{~cm}^{-1}$ is characteristic of a carbonyl group. This first FTIR-ATR analysis indicates the presence of aliphatic hydrocarbons combined with a peptide moiety that is characteristic of lipopeptide biosurfactants, as it has been previously described in the literature $[34,36]$.

\subsection{2. ${ }^{1} \mathrm{H}$ NMR spectroscopy}

The characterization of biosurfactants produced by $B$. subtilis strains using NMR spectroscopy has been described in the literature [38-40]. Therefore, the composition of biosurfactants obtained from isolates \#309, \#311 and \#573 was probed by ${ }^{1} \mathrm{H}$ NMR analysis (Fig. 2).

The three spectra showed two main regions corresponding to resonance of $\alpha$-carbon protons (3.5-5.5 ppm) and side-chain protons $(0.25-3.0 \mathrm{ppm})[41,42]$. The differences observed in the spectra are in chemical shifts from the region correspondent to the amide protons (6.5-10 ppm), in which the NMR spectrum is less defined. All spectra showed some similarity with the standard surfactin (spectra for standard surfactin reported by Wei and Chu [43]). However, it is clear the presence of distinct regions relatively to the standard molecule, as well as among the three biosurfactant extracts herein studied. The intense singlet at $3.47 \mathrm{ppm}$ observed in the biosurfactants extracted from isolates \#311 and \#573 is similar with that observed in ${ }^{1} \mathrm{H}$ NMR spectra of lipopeptide monoesters previously reported in literature [38-40], thus suggesting the presence of one $\mathrm{OCH}_{3}$ group in those biosurfactants. The presence of the methyl esters in the structure of surfactins has been related with an increase of its hydrophobicity and, consequently an increment of their surfactant powers, antifungal and hemolytic activities [39]. On the other hand, for the three extracts, an intense singlet at $5.28 \mathrm{ppm}$ (5.30 ppm for isolate \#309) was observed. This resonance probably corresponds to the $\mathrm{H}-3$ (terminal proton) of the fatty acid chain, which has also been previously observed by other authors $[39,40]$. 

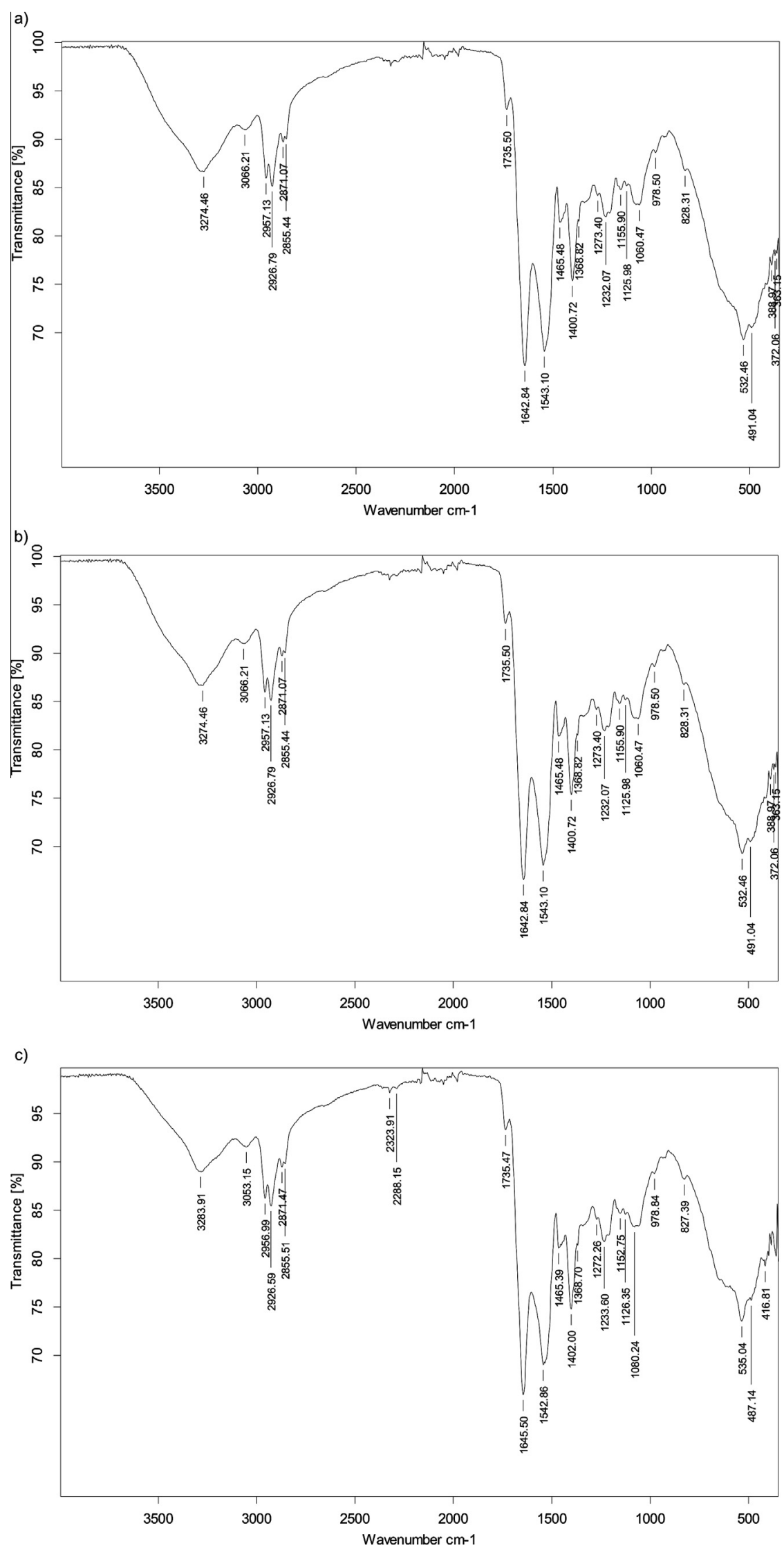

Fig. 1. FTIR-ATR spectra for biosurfactant extracts produced by isolates \#309 (a), \#311 (b) and \#573 (c). 
(a)

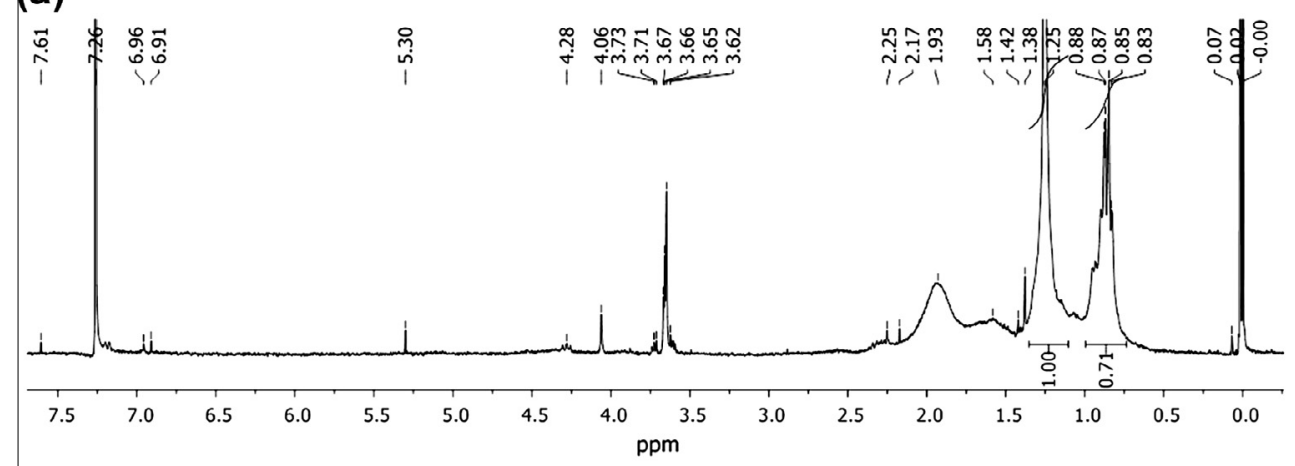

(b)
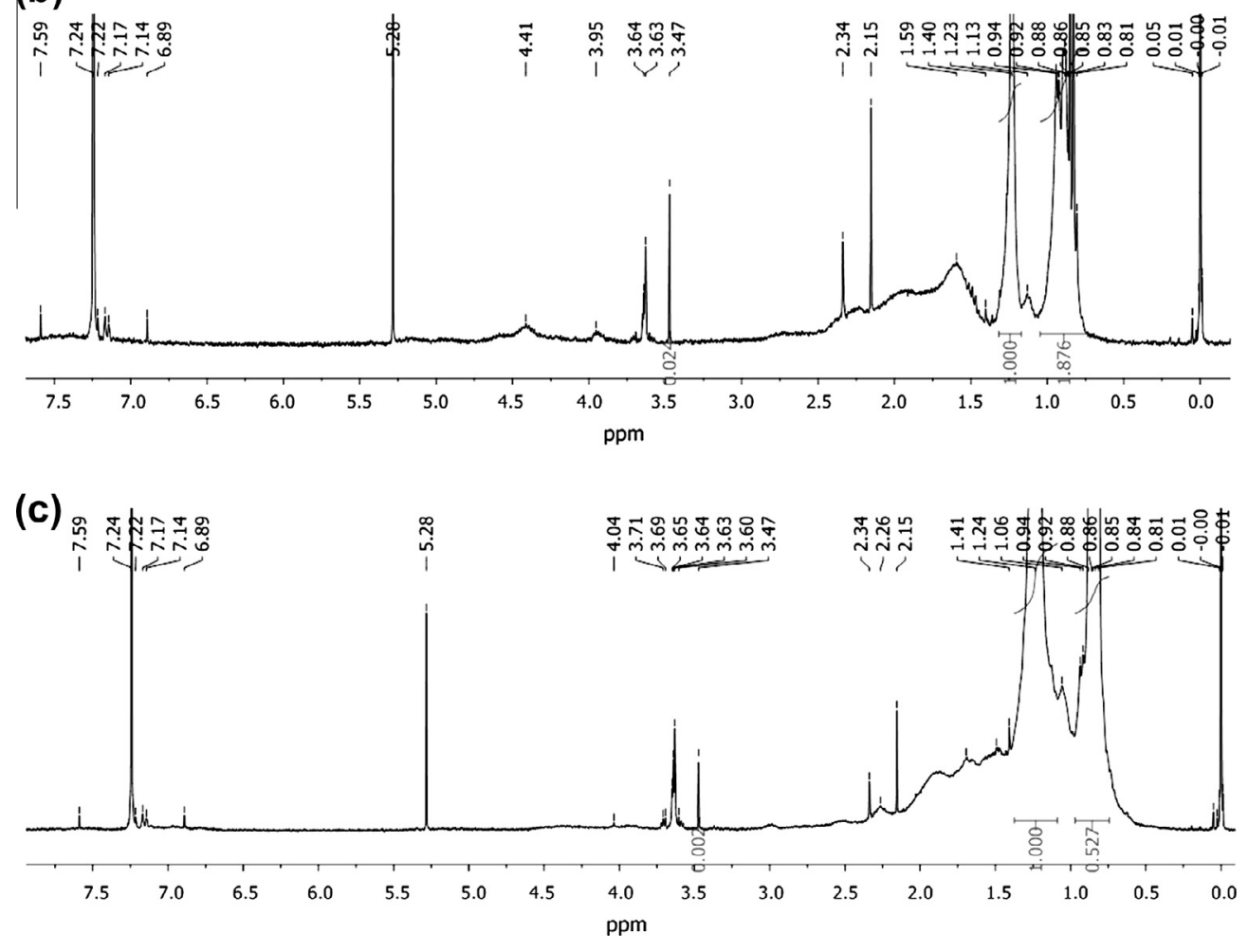

Fig. 2. ${ }^{1} \mathrm{H}$ NMR spectra for biosurfactant extracts produced by B. subtilis isolates \#309 (a), \#311 (b) and \#573 (c).

The integral relation of the two different regions of aliphatic chains (approximately $1.55-1.25 \mathrm{ppm}$ and $0.80-0.90 \mathrm{ppm}$ ) can give an important correlation between the presence of $n$-surfactin and iso- or/and anteiso-sufactins. The results showed a higher presence of iso forms in the biosurfactants recovered from the supernatant of the isolate \#311, and lower concentrations of those forms in the biosurfactant recovered from isolate \#573. According to Youssef et al. [44], the surface activity of lipoheptapeptides with structures analogous to surfactin increases when the ratio of iso- to normal-even-numbered fatty acids is increased. In our case, lower surface tension values ( $\mathrm{ST}^{-2}$ ) and $\mathrm{CMC}$ were obtained for isolate \#311 when compared with the isolate \#573. However, for lichenysin, iturin and mycosubtilin an opposite behavior has been reported, and an increase in the percentage of branched-chain fatty acids was found to decrease the activity of the biosurfactant, whereas an increase in the percentage of straight-chains increased their surface activity [39]. This may be due to the different amino acid composition of those biosurfactants, which can result in different properties.

The ${ }^{1} \mathrm{H}$ NMR analysis of the different biosurfactant extracts produced by different isolates demonstrated the presence of different surfactins mixtures, supporting the different surface activities and emulsifying properties previously discussed. Each surfactin mixture obtained with the Bacillus isolates herein studied was further characterized by mass spectrometry.

\subsubsection{Mass spectrometry}

The MALDI-TOF spectra of the biosurfactants obtained from each isolate (\#309, \#311 and \#573) are shown in Fig. 3. The three mass spectra show that there are one well-resolved group of peaks at $m / z$ values between 1000 and 1060 . This group could be attributed to the different variants of surfactins, as previously described by Vater et al. [45]. Each surfactin mixture extract has peaks which can be attributed to the protonated forms, with sodium adducts. Each isolate spectrum displays three $[\mathrm{M}+\mathrm{Na}]^{+}$peaks at $\mathrm{m} /$ $z=1030.6,1044.6$ and 1058.7, that correspond to the heptapeptide moiety (L-Glu-L-Leu-D-Leu-L-Val-L-Asp-D-Leu-L-Leu) characteristic of surfactins, linked to a $\mathrm{C}_{13}, \mathrm{C}_{14}$ or $\mathrm{C}_{15}$ hydroxy fatty acid chain, respectively (Fig. 4). The spectra here reported are very similar to those obtained by Vater et al. [45] and Leenders et al. [46]. In addition, it is possible to observe the presence of other surfactins in the extract mixtures, although in lower amounts. These results confirm 

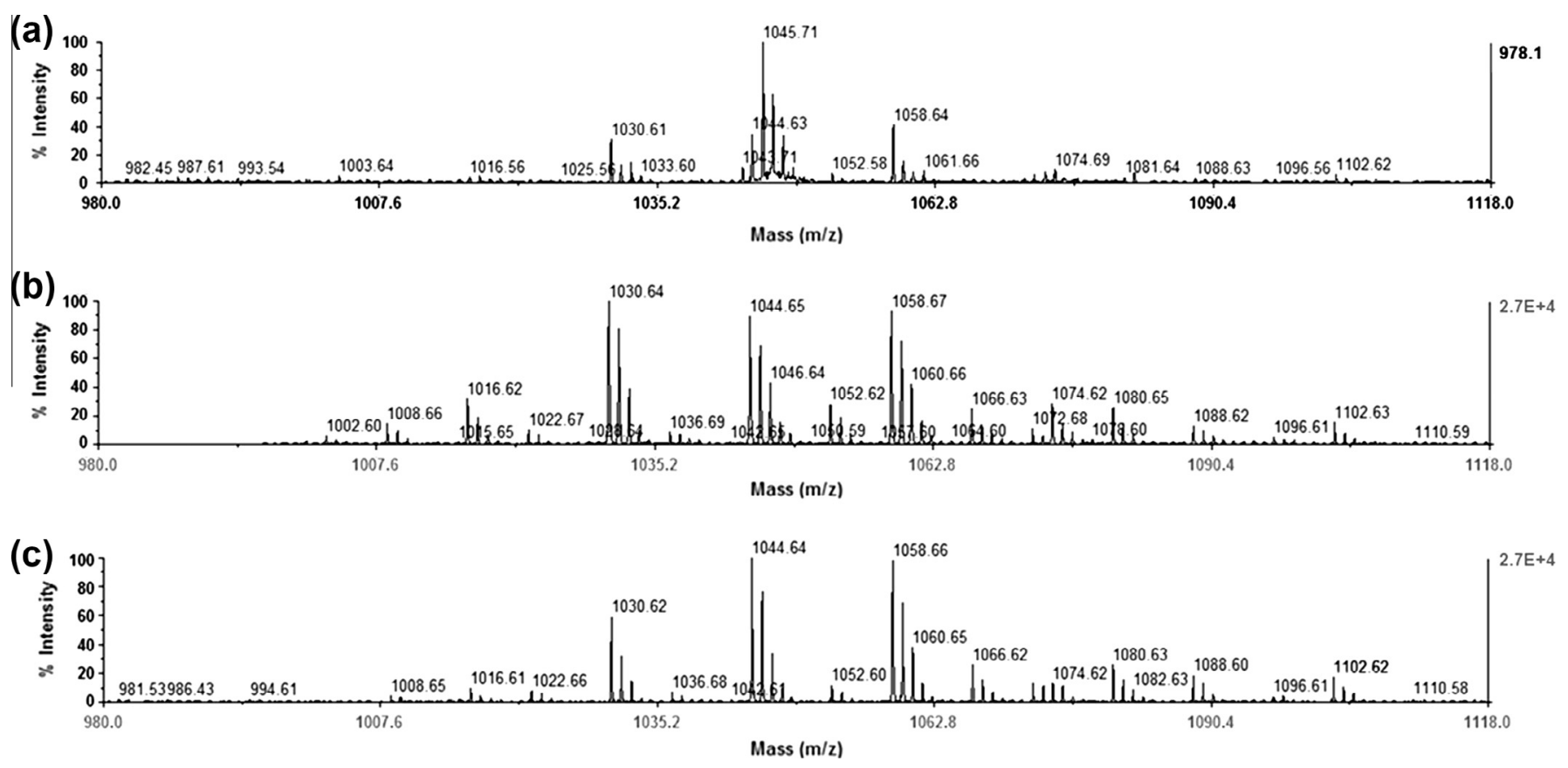

Fig. 3. MALDI-TOF spectra for surfactin-like extracts produced by B. subtilis isolates \#309 (a), \#311 (b) and \#573 (c).

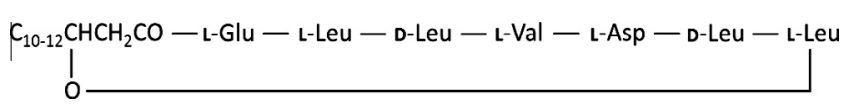

Fig. 4. Structure of surfactin.

the data previously obtained by ${ }^{1} \mathrm{H}$ NMR spectra, where it was clearly shown the presence of some mono-methyl ester surfactins, as well as the existence of different types of biosurfactants with different properties synthesized by the three isolates studied. Furthermore, comparing the three different spectra (Fig. 3) it was possible to found similarity between the mixtures obtained by isolate $\# 311$ and \#573, in which approximate amounts of $\mathrm{C}_{13^{-}}, \mathrm{C}_{14^{-}}$, and $\mathrm{C}_{15}$-surfactin are visible. On the other hand, the spectrum of the biosurfactant produced by the isolate \#309 exhibited a more intense peak at 1045.7, corresponding to higher amounts of $\mathrm{C}_{14}$-surfactin in the mixture. Youssef et al. [44] showed that iso- $\mathrm{C}_{14}$ surfactin exhibits the optimum hydrophilic-lipophilic balance required for optimum surface activity. Also, Bacon et al. [47] reported that surfactins with $\mathrm{C}_{-14}$ acyl chains possess a higher surface activity. This could explain the higher efficiency of biosurfactants produced by isolate \#309 when compared with the isolate \#573.

\subsection{Interfacial water-oil tension properties}

To use these biosurfactants in MEOR processes it is important to first understand their interfacial properties in liquid-liquid equilibrium. Although several researchers have studied the surfaceactivities at air/water $[28,31-33,48,49]$ and the oil/water/rock systems wettability (by the contact angle measurement) [50,51], only few reports present information on the properties of lipopeptides at the liquid/liquid interfaces [52,53]. Therefore, to overcome this scarcity, the interfacial tension of a water/oil system was studied for each crude biosurfactant at different concentrations (Fig. 5). The analysis of the interfacial tension values showed that the biosurfactants produced by the isolates \#311 and \#573 exhibit a similar ability to decrease the IFT of the Arabian light crude oil/water system. These two biosurfactant mixtures only showed surfactant activities above their CMC $\left(0.02\right.$ and $0.03 \mathrm{~g} \mathrm{l}^{-1}$, respectively, as determined in our previous work [28]), while in the case of the biosurfactant produced by the isolate \#309 it occurred a slight decrease of the IFT before the CMC was reached $\left(0.02 \mathrm{~g} \mathrm{l}^{-1}\right.$ [28]), being this decrease more significant afterwards. This may be due to the higher percentage of $\mathrm{C}_{14}$-surfactin in the mixture of biosurfactants produced by this isolate, as discussed previously, whereas the similar interfacial-activities observed with the biosurfactants produced by \#311 and \#573 are in accordance with their surfactin composition, earlier characterized by ${ }^{1} \mathrm{H}$ NMR and mass spectrometry. The three biosurfactant mixtures were found to reduce the IFT values up to $5 \mathrm{mN} \mathrm{m}^{-1}$. However, higher IFT decreases were expected based on reports from the literature [52]. Yet, the methodology herein used presents some limitations regarding the drop formation, since for biosurfactant concentrations above $0.1 \mathrm{~g} \mathrm{l}^{-1}$ the drop is unstable originating its immediate release, thus for higher biosurfactant concentrations it was not possible to determine the IFT values. Regarding the chemical surfactants Enordet and Petrostep, their CMCs were found to be $1 \mathrm{~g} \mathrm{l}^{-1}$. For a concentration of $0.1 \mathrm{~g} \mathrm{l}^{-1}$ (the highest biosurfactant concentration tested) the IFT values were similar to those obtained with demineralised water (about $21 \mathrm{mN} \mathrm{m}^{-1}$ ), whereas for a concentration of $1 \mathrm{~g} \mathrm{l}^{-1}$, Enordet and Petrostep reduced the IFT to 6.0 and $10.5 \mathrm{mN} \mathrm{m}^{-1}$, respectively. The results obtained show that biosurfactants studied in this work are more efficient than chemical surfactants. Al-Bahry et al. [54] observed that surfactins produced by a $B$. subtilis strain grown on molasses reduced the IFT between water and $n$-hexadecane from 23 to $5 \mathrm{mN} \mathrm{m}^{-1}$ at a concentration of $2.2 \mathrm{~g} \mathrm{l}^{-1}$. However, when higher concentrations of biosurfactant were used, the IFT was reduced up to $1 \mathrm{mN} \mathrm{m}^{-1}$. Deleu et al. [52] reported the reduction of the dodecane/water IFT to values around $2 \mathrm{mN} \mathrm{m}^{-1}$ using surfactin produced by $B$. subtilis, being this reduction higher than the observed with other biosurfactants, such as iturin A $\left(14.94 \mathrm{mN} \mathrm{m}^{-1}\right)$ and fengycin $\left(11.63 \mathrm{mN} \mathrm{m}^{-1}\right)$. Urum and Pekdemir [53] studied the ability of several biosurfactants to decrease the IFT of Ekofisk crude oil and reported that biosurfactants have a higher potential than the chemical surfactant SDS $\left(7.0 \mathrm{mN} \mathrm{m}^{-1}\right)$, as for example lecithin $\left(5.0 \mathrm{mN} \mathrm{m}^{-1}\right)$, rhamnolipid $\left(4.5 \mathrm{mN} \mathrm{m}^{-1}\right)$, saponin $\left(6.0 \mathrm{mN} \mathrm{m}^{-1}\right)$ and tannin $\left(4.5 \mathrm{mN} \mathrm{m}^{-1}\right)$. In summary, the reduction of IFT observed indicates the ability of the surfactin mixtures produced by the three $B$. subtilis isolates herein studied to 

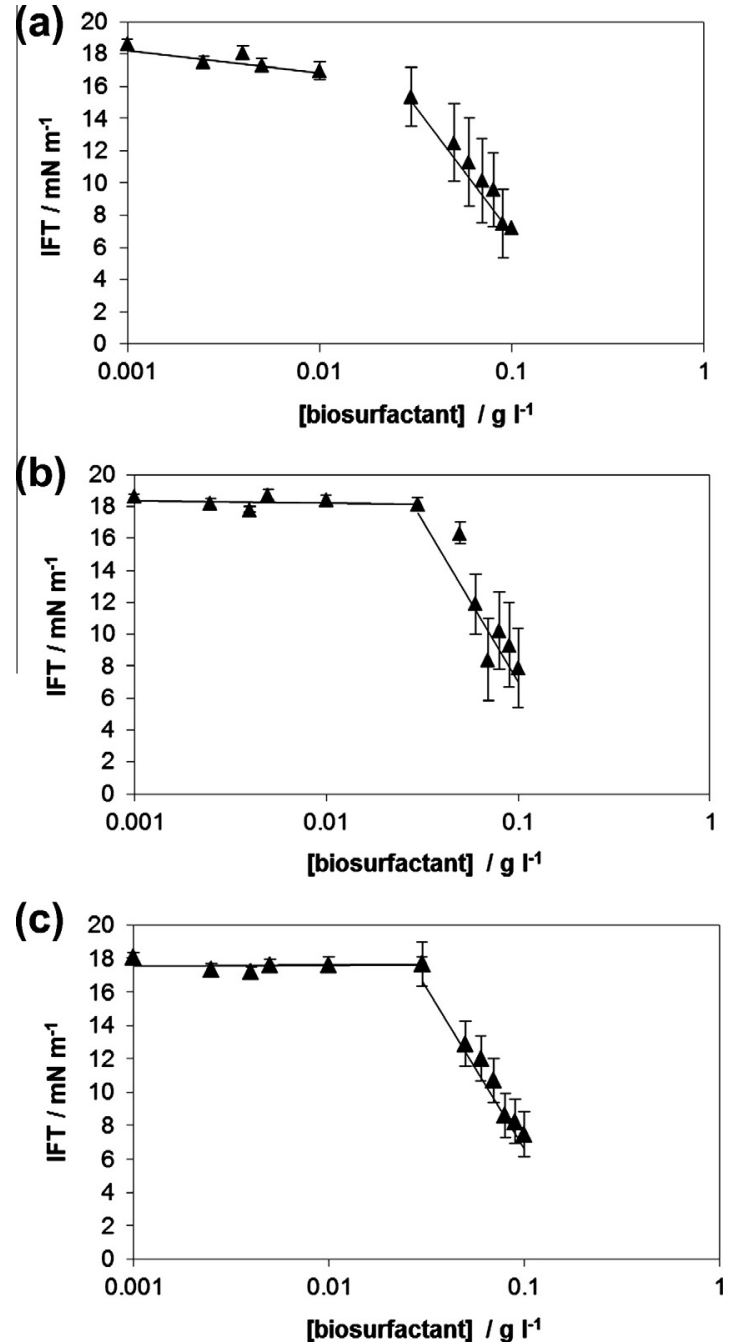

Fig. 5. Interfacial tension values $\left(\mathrm{mN} \mathrm{m}^{-1}\right)$ versus logarithm of biosurfactant concentration $\left(\mathrm{g} \mathrm{l}^{-1}\right)$ for each biosurfactant extract from B. subtilis isolates \#309 (a), \#311 (b) and \#573 (c).

Table 3

Percentages of oil recovered by the different biosurfactants and chemical surfactants at a concentration of $1 \mathrm{~g} \mathrm{l}^{-1}$. Results represent the average of three independent experiments \pm standard deviation.

\begin{tabular}{lc}
\hline Biosurfactant/chemical surfactant & \% of oil recovered \\
\hline B. subtilis \#309 & $22.1 \pm 2.4$ \\
B. subtilis \#311 & $19.0 \pm 1.6$ \\
B. subtilis \#573 & $18.8 \pm 1.1$ \\
Enordet & $11.7 \pm 1.9$ \\
Petrostep & $8.7 \pm 1.3$ \\
Control & $0.0 \pm 0.0$ \\
\hline
\end{tabular}

remove oil from reservoir. As the IFT between crude oil and water is reduced, the capillary force between the oil and the reservoir rock is also reduced. Therefore, this reduction leads to an increased mobilization of the oil in the reservoir which is of great interest to enhance oil recovery in mature reservoirs.

\subsection{Application of chemical surfactants and biosurfactants in removal of crude oil from sand}

The performance of biosurfactants and chemical surfactants in oil recovery was studied using crude oil contaminated sand. As can be seen from the results obtained (Table 3 ), the different biosurfactants at a concentration of $1 \mathrm{~g} \mathrm{l}^{-1}$ recovered between $19 \%$ and $22 \%$ of oil, whereas the recoveries obtained with the chemical surfactants at the same concentration were between $9 \%$ and $12 \%$. From the results obtained it can be concluded that these biosurfactants are more effective in oil recovery when compared with the chemical surfactants Enordet and Petrostep.

\section{Conclusion}

In the current work, the biosurfactant production by three $B$. subtilis strains was optimized using different carbon and nitrogen sources. The strains were found to produce biosurfactants with better surface-activities and emulsification properties when sucrose was used as carbon source. Crude biosurfactant mixtures were found to be mainly constituted of surfactins with an heptapeptide moiety (L-Glu-L-Leu-D-Leu-L-Val-L-Asp-D-Leu-L-Leu), linked to a $\mathrm{C}_{13}, \mathrm{C}_{14}$ or $\mathrm{C}_{15}$ hydroxy fatty acid chain. Although several similarities were found among the biosurfactant mixtures produced by the different isolates, it was evident the presence of different variants of surfactins that could be implicated in the distinct emulsification and surface-active properties found. These biosurfactant mixtures were able to decrease the interfacial tension of Arabian light crude oil/water system more efficiently than chemical surfactants, and showed better results in oil recovery, thus suggesting their interest for use in MEOR processes.

\section{Acknowledgements}

This work was supported by PARTEX OIL AND GAS. Jorge F.B. Pereira acknowledges the financial support from Fundação para a Ciência e a Tecnologia through doctoral research grant SFRH/BD/ $60228 / 2009$. Rui Vitorino acknowledges the financial support from QOPNA and RNEM by the Fundação para a Ciência e a Tecnologia.

\section{References}

[1] Banat IM, Makkar RS, Cameotra SS. Potential commercial applications of microbial surfactants. Appl Microbiol Biotechnol 2000;53:495-508.

[2] Singh A, Van Hamme JD, Ward OP. Surfactants in microbiology and biotechnology: Part 2. Application aspects. Biotechnol Adv 2007;25:99-121.

[3] Desai JD, Banat IM. Microbial production of surfactants and their commercial potential. Microbiol Mol Biol Rev 1997;61:47-64.

[4] Nitschke M, Costa SGVAO, Contiero J. Rhamnolipid surfactants: an update on the general aspects of these remarkable biomolecules. Biotechnol Progr 2005;21:1593-600.

[5] Mukherjee S, Das P, Sen R. Towards commercial production of microbial surfactants. Trends Biotechnol 2006;24:509-15.

[6] Van Hamme JD, Singh A, Ward OP. Physiological aspects. Part 1 in a series of papers devoted to surfactants in microbiology and biotechnology. Biotechnol Adv 2006;24:604-20.

[7] Shete AM, Wadhawa G, Banat IM, Chopade BA. Mapping of patents on bioemulsifier and biosurfactant: a review. I Sci Ind Res India 2006:65:91-115.

[8] Makkar RS, Cameotra SS, Banat IM. Advances in utilization of renewable substrates for biosurfactant production. AMB Express 2011;1:5.

[9] Meyer HP. Sustainability and biotechnology. Org Process Res Dev $2011 ; 15: 180-8$.

[10] Fox SL, Bala GA. Production of surfactant from Bacillus subtilis ATCC 21332 using potato substrates. Bioresour Technol 2000;75:235-40.

[11] Bustos G, de la Torre N, Moldes AB, Cruz JM, Domínguez JM. Revalorization of hemicellulosic trimming vine shoots hydrolyzates trough continuous production of lactic acid and biosurfactants by Lactobacillus pentosus. J Food Eng 2007;78:405-12.

[12] Rodrigues LR, Teixeira JA, Oliveira R. Low cost fermentative medium for biosurfactant production by probiotic bacteria. Biochem Eng J 2006;32:135-42.

[13] Gudiña EJ, Teixeira JA, Rodrigues LR. Biosurfactant-producing lactobacilli: screening, production profiles and effect of medium composition. Appl Environ Soil Sci 2011. http://dx.doi.org/10.1155/2011/201254.

[14] Rodrigues LR, Teixeira JA. Biosurfactants production from cheese whey. In: Cerdán ME, González-Siso M, Becerra M, editors. Advances in Cheese Whey Utilization. Kerala, India: Transworld Research Network Publishers; 2008. p. 81-104.

[15] Pereira JFB, Gudiña EJ, Doria ML, Domingues MR, Rodrigues LR, Teixeira JA, et al. Characterization by electrospray ionization and tandem mass spectrometry of rhamnolipids produced by two Pseudomonas aeruginosa 
strains isolated from Brazilian crude oil. Eur J Mass Spectrom 2012;18:399-406

[16] Nitschke M, Pastore GM. Production and properties of a surfactant obtained from Bacillus subtilis grown on cassava wastewater. Bioresour Technol 2006;97:336-41.

[17] Vaz DA, Gudiña EJ, Alameda EJ, Teixeira JA, Rodrigues LR. Performance of a biosurfactant produced by a Bacillus subtilis strain isolated from crude oil samples as compared to commercial chemical surfactants. Colloids Surf B Biointerfaces 2012;89:167-74.

[18] Dufour S, Deleu M, Nott K, Wathelet B, Thonart P, Paquot M. Hemolytic activity of new linear surfactin analogs in relation to their physico-chemical properties. Biochim Biophys Acta 2005;1726:87-95.

[19] Seydlová G, Svobodová J. Review of surfactin chemical properties and the potential biomedical applications. Cent Eur J Med 2008;3:123-33.

[20] Rodrigues LR, Banat IM, Teixeira JA, Oliveira R. Biosurfactants: potential applications in medicine. J Antimicrob Chemother 2006;57:609-18.

[21] Vollenbroich D, Ozel M, Vater J, Kamp RM, Pauli G. Mechanism of inactivation of enveloped viruses by the biosurfactant surfactin from Bacillus subtilis. Biologicals 1997;25:289-97.

[22] Cooper DG, Macdonald CR, Duff SJB, Kosaric N. Enhanced production of surfactin from Bacillus subtilis by continuous product removal and metal cation additions. Appl Environ Microbiol 1981;42:408-12.

[23] Banat IM, Franzetti A, Gandolfi I, Bestetti G, Martinotti MG, Fracchia L, et al. Microbial biosurfactants production, applications and future potential. Appl Microbiol Biotechnol 2010;87:427-44.

[24] Simpson DR, Natraj NR, McInerney MJ, Duncan KE. Biosurfactant-producing Bacillus are present in produced brines from Oklahoma oil reservoirs with a wide range of salinities. Appl Microbiol Biotechnol 2011;91:1083-93.

[25] Youssef N, Elshahed MS, McInerney MJ. Microbial processes in oil fields: culprits, problems, and opportunities. Adv Appl Microbiol 2009;66:141-251.

[26] Yakimov MM, Timmis KN, Wray V, Fredrickson HL. Characterization of a new lipopeptide surfactant produced by thermotolerant and halotolerant subsurface Bacillus licheniformis BAS50. Appl Environ Microbiol 1995;61:1706-13.

[27] Ghojavand H, Vahabzadeh F, Mehranian M, Radmehr M, Shahraki KA, Zolfagharian $\mathrm{F}$, et al. Isolation of thermotolerant, halotolerant, facultative biosurfactant-producing bacteria. Appl Microbiol Biotechnol 2008;80:1073-85.

[28] Gudiña EJ, Pereira JFB, Rodrigues LR, Coutinho JAP, Teixeira JA. Isolation and study of microorganisms from oil samples for application in microbial enhanced oil recovery. Int Biodeterior Biodegrad 2012;68:56-64.

[29] Gudiña EJ, Teixeira JA, Rodrigues LR. Isolation and functional characterization of a biosurfactant produced by Lactobacillus paracasei. Colloids Surf B Biointerfaces 2010;76:298-304.

[30] Folch J, Lees M, Stanley GHS. A simple method for the isolation and purification of total lipides from animal tissues. J Biol Chem 1957;226:497-509.

[31] Abdel-Mawgoud AM, Aboulwafa MM, Hassouna NAH. Optimization of surfactin production by Bacillus subtilis isolate BS5. Appl Biochem Biotechnol 2008;150:305-25.

[32] Makkar RS, Cameotra SS. Biosurfactant production by a thermophilic Bacillus subtilis strain. J Ind Microbiol Biotechnol 1997;18:37-42.

[33] Dastgheib SMM, Amoozegar MA, Elahi E, Asad S, Banat IM. Bioemulsifier production by a halothermophilic Bacillus strain with potential applications in microbially enhanced oil recovery. Biotechnol Lett 2008;30:263-70.

[34] Joshi S, Bharucha C, Desai AJ. Production of biosurfactant and antifungal compound by fermented food isolate Bacillus subtilis 20B. Bioresour Technol 2008;99:4603-8

[35] Ghribi D, Ellouze-Chaabouni S. Enhancement of Bacillus subtilis lipopeptide biosurfactants production through optimization of medium composition and adequate control of aeration. Biotechnol Res Int 2011. http://dx.doi.org/ $10.4061 / 2011 / 653654$
[36] Faria AF, Teodoro-Martinez DS, Barbosa GNO, Vaz BG, Silva IS, Garcia JS, et al Production and structural characterization of surfactin (C14/Leu7) produced by Bacillus subtilis isolate LSFM-05 grown on raw glycerol from the biodiese industry. Process Biochem 2011;46:1951-7.

[37] Sousa M, Melo VMM, Rodrigues S, Sant'ana HB, Gonçalves LRB. Screening of biosurfactant-producing Bacillus strains using glycerol from the biodiesel synthesis as main carbon source. Bioprocess Biosyst Eng 2012;35:897-906.

[38] Tang JS, Gao H, Hong K, Yu Y, Jiang MM, Lin HP, et al. Complete assignments of $\mathrm{H}-1$ and C-13 NMR spectral data of nine surfactin isomers. Magn Reson Chem 2007;45:792-6.

[39] Kowall M, Vater J, Kluge B, Stein T, Franke P, Ziessow D. Separation and characterization of surfactin isoforms produced by Bacillus subtilis OKB 105 . J Colloid Interface Sci 1998;204:1-8.

[40] Liu XY, Yang SZ, Mu BZ. Production and characterization of a C-15-surfactin-Omethyl ester by a lipopeptide producing strain Bacillus subtilis HSO121. Process Biochem 2009;44:1144-51.

[41] Peypoux F, Bonmatin JM, Labbé H, Das BC, Ptak M, Michel G. Isolation and characterization of a new variant of surfactin, the [Val7]surfactin. Eur Biochem 1991;202:101-6.

[42] Chen HL, Juang RS. Recovery and separation of surfactin from pretreated fermentation broths by physical and chemical extraction. Biochem Eng 2008;38:39-46.

[43] Wei YH, Chu IM. Enhancement of surfactin production in iron-enriched media by Bacillus subtilis ATCC 21332. Enzyme Microb Technol 1998;22:724-8.

[44] Youssef NH, Duncan KE, McInerney MJ. Importance of 3-hydroxy fatty acid composition of lipopeptides for biosurfactant activity. Appl Environ Microbiol 2005;71:7690-5.

[45] Vater J, Kablitz B, Wilde C, Franke P, Mehta N, Cameotra SS. Matrixassisted laser desorption ionization-time of flight mass spectrometry of lipopeptide biosurfactants in whole cells and culture filtrates of Bacillus subtilis C-1 isolated from petroleum sludge. Appl Environ Microbiol 2002;68:6210-9.

[46] Leenders F, Stein TH, Kablitz B, Franke P, Vater J. Rapid typing of Bacillus subtilis strains by their secondary metabolites using matrix-assisted laser desorption ionization mass spectrometry of intact cells. Rapid Commun Mass Spectrom 1999;13:943-9.

[47] Bacon CW, Hinton DM, Mitchell TR, Snook ME, Olubajo B. Characterization of endophytic strains of Bacillus mojavensis and their production of surfactin isomers. Biol Control 2012;62:1-9.

[48] Maget-Dana R, Ptak M. Interfacial properties of surfactin. J Colloid Interface Sci 1992;153:285-91.

[49] Thimon L, Peyoux F, Maget-Dana R, Michel G. Surface-active properties of antifungal lipopeptides produced by Bacillus subtilis. J Am Oil Chem Soc 1992:69:92-3.

[50] Karimi M, Mahmoodi M, Niazi A, Al-Wahaibi Y, Ayatollahi S. Investigating wettability alteration during MEOR process, a micro/macro scale analysis. Colloids Surf B Biointerfaces 2012;95:129-36.

[51] Ismail W, Al-Rowaihi IS, Al-Humam AA, Hamza RY, El Nayal AM, Bououdina, M. Characterization of a lipopeptide biosurfactant produced by a crude-oilemulsifying Bacillus sp. I-15. Int Biodeter Biodegr 2012. http://dx.doi.org/ 10.1016/j.ibiod.2012.04.017.

[52] Deleu M, Razafindralambo H, Popineau Y, Jacques P, Thonart P, Paquot M Interfacial and emulsifying properties of lipopeptides from Bacillus subtilis Colloid Surf A: Physicochem Eng Aspects 1999;152:3-10.

[53] Urum K, Pekdemir T. Evaluation of biosurfactants for crude oil contaminated soil washing. Chemosphere 2004;57:1139-50.

[54] Al-Bahry N, Al-Wahaibi YM, Elshafie AE, Al-Bemani AS, Joshi SJ, Al-Makhmari HS, et al. Biosurfactant production by Bacillus subtilis B20 using date molasses and its possible application in enhanced oil recovery. Int Biodeter Biodegrad 2013;80:141-6. 